\title{
Frutanos em calos de Smallanthus sonchifolius (Poepp.) H. Rob.
}

\author{
Vanessa Fátima de Oliveira ${ }^{1}$, Nair Massumi Itaya ${ }^{2}$, Eny Iochevet Segal Floh ${ }^{3}$ \\ e Maria Angela Machado de Carvalho ${ }^{1,4}$
}

Recebido: 06.06.2008; aceito: 05.02.2009

\begin{abstract}
Fructans in calli of Smallanthus sonchifolius (Poepp.) H. Rob.). Smallanthus sonchifolius is an Asteraceae native from the Andes Mountains that accumulates inulin-type fructans in the underground reserve organs, the tuberous roots and the rhizophores. Yellow callus was obtained from tuberous roots, giving origin, spontaneously to red callus. Fructans and their metabolizing enzymes were analyzed in calli of both types, showing similar fructan contents in both lineages. However, synthesizing activity was higher in red callus, while hydrolyzing activity was higher in yellow callus. HPAEC/ PAD analyses revealed the presence of fructo-oligosaccharides in both calli with degrees of polymerization lower than those found in plants cultured ex vitro, indicating that this characteristic was maintained in undifferentiated cells. The presence of fructans and the differences between the activities of fructosyltransferases and hydrolases found in red and yellow calli indicate this material as suitable for studies of fructan metabolism under controlled conditions.
\end{abstract}

Key words: fructan, in vitro conditions, inulin, yacon

RESUMO - (Frutanos em calos de Smallanthus sonchifolius (Poepp.) H. Rob.). Smallanthus sonchifolius, Asteraceae originária dos Andes, possui rizóforos e raízes tuberosas que armazenam frutanos do tipo inulina. Explantes de raízes tuberosas dão origem a calos de linhagem amarela que, espontaneamente, originaram a linhagem vermelha. O conteúdo de frutanos foi semelhante nas duas linhagens, enquanto a atividade de síntese foi mais elevada na linhagem vermelha e a de hidrólise foi mais elevada na amarela. Análises por HPAEC/PAD demonstraram a presença, em ambos os calos, de frutooligossacarídeos com grau de polimerização inferior ao encontrado em plantas cultivadas sob condições naturais, indicando que esta característica é mantida em células indiferenciadas. A presença de frutanos e as diferenças entre as atividades de frutosiltransferases e hidrolases em calos vermelhos e amarelos possibilitam a aplicação desse material em estudos de regulação do metabolismo desses compostos em condições controladas.

Palavras-chave: cultivo in vitro, frutanos, inulina, yacon

\section{Introdução}

A maioria das plantas armazena amido ou sacarose como carboidrato de reserva, porém, aproximadamente $15 \%$ das angiospermas armazenam frutanos, incluindo as ordens mais evoluídas como Poales e Asterales (Hendry \& Wallace 1993). Muitas das plantas que contém frutanos, como o trigo, a cebola, o alho-poró, a alcachofra, a chicória, a alface, a bardana e o aspargo, têm sido utilizadas há séculos para fins medicinais ou alimentares (Fuchs 1993). Os frutanos consistem de séries homólogas de oligo- e polissacarídeos de frutose originados da sacarose. Diferentes frutanos podem ser encontrados, dependendo da ligação entre as unidades de frutose. Nas inulinas, comumente presentes em Asteraceae, o tipo de ligação predominante é $\beta$ (2-1) (Pollock et al. 1996).

Os frutanos são sintetizados pela sacarose: sacarose 1-frutosiltransferase (1-SST - EC 2.4.1.99), que catalisa irreversivelmente a formação do trissacarídeo 1-cestose a partir de duas moléculas de sacarose, liberando uma molécula de glucose, e pela frutano: frutano frutosiltransferase (1-FFT - EC 2.4.1.100), que catalisa a transferência reversível de resíduos terminais de frutose de uma molécula doadora para uma receptora. A despolimerização dos

1. Instituto de Botânica, Caixa Postal 3005, 01061-970 São Paulo, SP, Brasil

2. Universidade do Grande ABC, Av. Industrial, 3330, 09080-511 Santo André, SP, Brasil

3. Universidade de São Paulo, Instituto de Biociências, Caixa Postal 11461, 05422-970 São Paulo, SP, Brasil

4. Autor para correspondência: mam.carvalho@gmail.com 
frutanos é catalisada por uma frutano-exohidrolase (1FEH - EC 3.2.1.153), que atua na remoção seqüiencial dos resíduos terminais de frutose (Edelman \& Jefford 1968, Van den Ende et al. 2002).

O interesse crescente no uso de inulina na alimentação levou a um aumento de 1.000 para mais de 100.000 toneladas na sua produção na última década, a partir de raízes de Cichorium intybus L. (chicória) (Van den Ende et al.2002). Quando misturada à água, a inulina forma uma emulsão de baixo teor calórico com textura similar à da gordura e adequada à fabricação de iogurtes, sorvetes, mousses, chocolates e produtos de panificação (Ritsema \& Smeekens 2003). Os frutooligossacarídeos (FOS), por sua vez, são fibras solúveis dietéticas não digeridas na parte superior do trato gastrointestinal (Carabin \& Flamm 1999) e fermentados seletivamente no intestino grosso, estimulando o crescimento de bifidobactérias (Hidaka et al. 1986, Wang \& Gibson 1993). Neste processo são liberados compostos que aumentam a resistência imunológica do hospedeiro e a absorção de minerais, particularmente o cálcio, diminuem a síntese de triglicérides e ácidos graxos no fígado e conseqüentemente o nível desses compostos no sangue (Kaur \& Gupta 2002).

Smallanthus sonchifolius (Poepp.) H. Rob. (= Polymnia sonchifolia), popularmente conhecida por yacon, é uma espécie herbácea, da família Asteraceae, nativa dos vales andinos da Colômbia, Equador, Peru, Bolívia e noroeste da Argentina, de altitudes que variam de 2.000 a 3.100 m. O sistema subterrâneo desta planta é constituído de rizóforos, utilizados na propagação vegetativa, e de raízes tuberosas, que são os principais órgãos de armazenamento (Grau \& Rea 1998, Vilhena et al. 2000). Ambas as estruturas acumulam frutanos do tipo inulina, porém, diferentemente de $C$. intybus ou Helianthus tuberosus L. (alcachofra-de-jerusalém), que apresentam frutanos com grau de polimerização (GP) médio de aproximadamente 35 , os frutanos em yacon são FOS com GPde 3-15 (Goto et al. 1995, Itaya et al. 2002).

As plantas de yacon apresentam alta produtividade, podendo atingir $70 \mathrm{t} \mathrm{ha}^{-1}$ de raízes tuberosas por ano, segundo Nieto (1991), embora Kakihara et al. (1997) tenham relatado rendimentos de até 100 t ha $^{-1}$ de raízes tuberosas e $1 \mathrm{t} \mathrm{ha}^{-1}$ de folhas frescas. Introduzida no Brasil por volta de 1989 na região de Capão Bonito (SP), esta planta vem sendo cultivada atualmente em várias cidades do estado de São Paulo (Vilhena et al. 2000).

Os conteúdos elevados de frutose livre e de FOS nas raízes tuberosas constituíram forte motivo para a indicação de yacon como fonte de matéria prima para a produção de xaropes de frutose e de FOS (Ohyama et al. 1990). Suas raízes são utilizadas na medicina popular, principalmente devido à atividade antidiabética presente nas folhas e nas raízes tuberosas (Kakihara et al. 1997).

A micropropagação de plantas através das técnicas de cultura de tecidos in vitro tem sido utilizada como alternativa para a produção comercial de espécies ornamentais e medicinais com valor farmacológico reconhecido, além da manutenção de espécies em bancos de germoplasma (Chu \& Kurtz 1990). A cultura in vitro é, portanto, uma alternativa para a propagação de yacon, por possibilitar sua rápida multiplicação e manutenção das características genéticas das plantas selecionadas como matrizes (Grau \& Rea 1998).

A cultura de tecidos também é apontada como um instrumento valioso para o estudo do metabolismo primário e secundário, além de ser um sistema apropriado para a produção de compostos importantes como carboidratos solúveis e enzimas (Abou-Mandour et al. 1987, Veramendi et al. 1999). Por outro lado, a presença de frutanos em calos tem sido relatada de forma esparsa na literatura. Estudos pioneiros mostraram a presença de frutanos e suas características estruturais em calos de Symphytum officinale L. (AbouMandour et al. 1987), Phleum pratense L. (Hale et al. 1987) e Gomphrena macrocephala A. St.-Hil. (Vieira et al. 1995). Mais recentemente, Itaya et al. (2005) demonstraram a ocorrência de frutanos e a presença de atividade das enzimas SST e FFT em extratos de calos de Viguiera discolor Baker, Asteraceae do cerrado, ampliando o conhecimento sobre o metabolismo de frutanos em tecidos cultivados in vitro.

Considerando a elevada concentração de FOS nas raízes tuberosas de $S$. sonchifolius, a vasta aplicação desses compostos na indústria e a escassez de estudos sobre o metabolismo de frutanos em culturas de calos, o presente trabalho teve como objetivo investigar a presença de frutanos e das enzimas envolvidas no seu metabolismo em duas linhagens de calos (amarela e vermelha), obtidas a partir de raízes tuberosas de $S$. sonchifolius.

\section{Material e métodos}

Material vegetal - Calos de Smallanthus sonchifolius obtidos de explantes de raízes tuberosas de plantas coletadas em canteiros experimentais da Universidade Estadual Paulista (UNESP), campus Botucatu, foram cultivados no Laboratório de Biologia Celular do Departamento de Botânica da Universidade de São 
Paulo (USP). O material foi mantido em frascos do tipo "Wheaton", contendo $30 \mathrm{~mL}$ do meio básico MS62 (Murashige \& Skoog 1962), pH 5,8, suplementado com ácido naftalenoacético (3 mg $\left.\mathrm{L}^{-1}\right)$, benzilaminopurina $\left(1 \mathrm{mg} \mathrm{L}^{-1}\right)$, Phytage $\AA$ $\left(1,8 \mathrm{~g} \mathrm{~L}^{-1}\right)$ e sacarose $(2 \%)$. As culturas foram mantidas a $25 \pm 2{ }^{\circ} \mathrm{C}$ em fotoperíodo de $16 \mathrm{~h}$, sob um fluxo de luz de $45 \mu \mathrm{mol} \mathrm{m} \mathrm{m}^{-2} \mathrm{~s}^{-1}$. Três semanas após a inoculação, os primeiros calos apresentaram crescimento vigoroso e cor amarelada. Após 18 meses de cultivo, com repicagens sucessivas a cada três semanas, estes passaram a exibir regiões de coloração avermelhada, que foram isoladas e inoculadas sob as mesmas condições descritas acima. Sucessivamente, em subculturas destas porções, foi obtida a linhagem de cor vermelha (figura 1). Para manutenção das culturas, pequenos fragmentos de calos de ambas as linhagens foram inoculados a cada 21 dias em meio de cultura e mantidos sob as mesmas condições, sendo descartadas porções que apresentavam sinais de oxidação. Amostras de calos de ambas as linhagens foram congeladas em nitrogênio líquido e mantidas a $-80{ }^{\circ} \mathrm{C}$ até a realização das análises bioquímicas.

Extração e análise de frutanos - as extrações de frutanos foram realizadas em triplicata, conforme Carvalho et al. (1998), com as seguintes modificações. As frações aquosas e etanólicas foram reunidas, concentradas constituindo o extrato de carboidratos solúveis. Os conteúdos de frutose livre e ligada foram determinados pelo método de antrona modificado (Jermyn 1956), utilizando-se frutose (Sigma) (200 $\mu \mathrm{g} \mathrm{mL}^{-1}$ ) como padrão. Amostras dos carboidratos

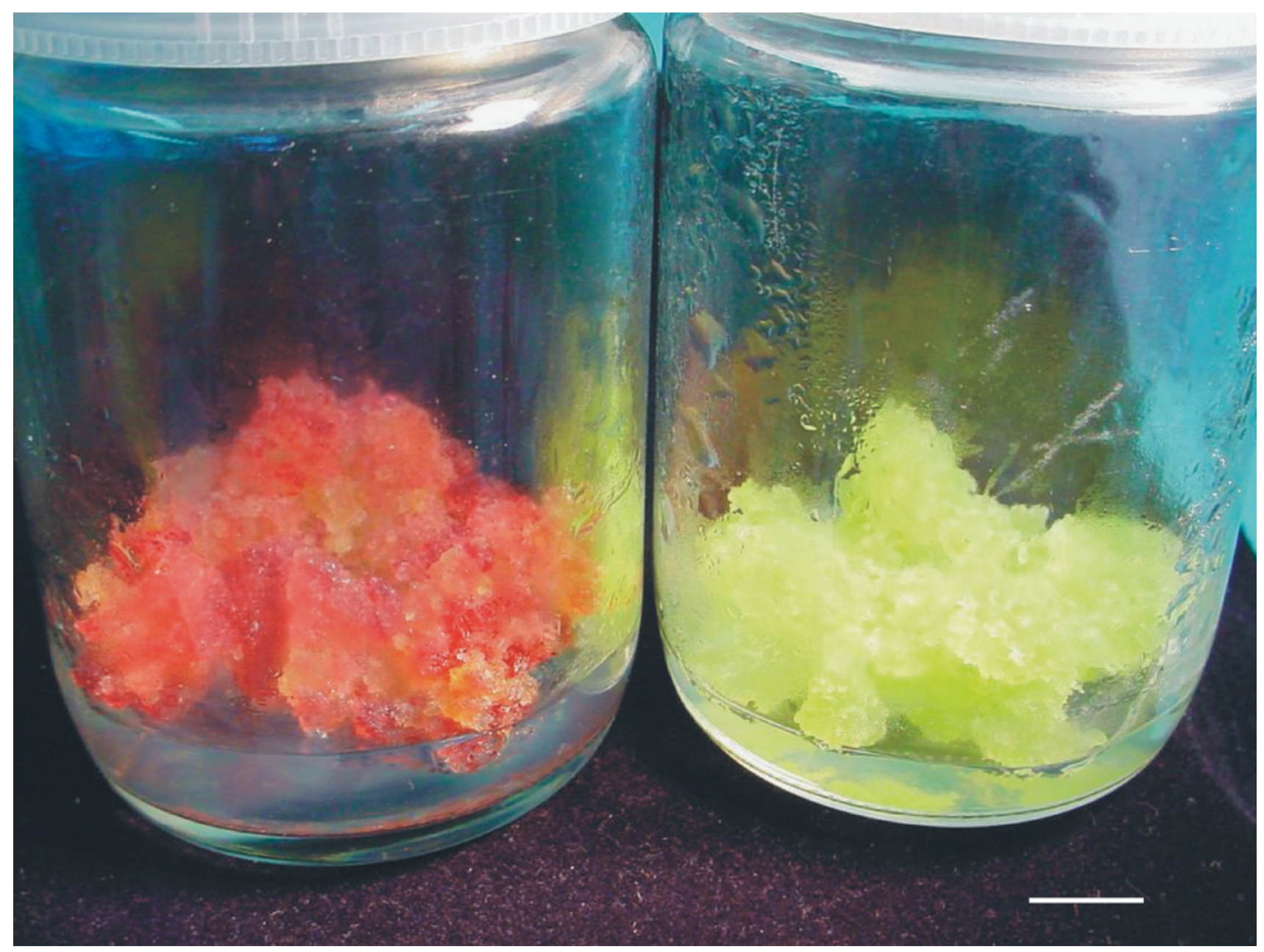

Figura 1. Calos de Smallanthus sonchifolius das linhagens vermelha e amarela (Barra de escala = 1,25 cm).

Figure 1. Calli of Smallanthus sonchifolius of the red and yellow lineages (Scale bar $=1.25 \mathrm{~cm}$ ). 
solúveis foram neutralizadas em colunas de troca iônica utilizando-se resinas Dowex na forma catiônica (50X8 - 200) e aniônica (1X8 - 200) e analisadas por cromatografia de troca aniônica de alta resolução e detector de pulso amperométrico (HPAEC/PAD) em sistema Dionex (modelo DX-300) e coluna Carbo Pac PA1 (4 X $250 \mathrm{~mm}$ ) a concentração de $400 \mu \mathrm{g} \mathrm{mL}^{-1}$, em equivalentes de frutose. A eluição foi realizada utilizando-se o gradiente de mistura do eluente A (150 $\mathrm{mM}$ de hidróxido de sódio) e eluente B (500 mM de acetato de sódio em $150 \mathrm{mM}$ de hidróxido de sódio) conforme Portes \& Carvalho (2006).

Extração enzimática e determinação da atividade enzimática - amostras de calos das linhagens vermelha e amarela foram homogeneizadas em tampão citrato-

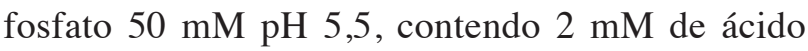
etilenodiamino tetra-acético (EDTA), $5 \mathrm{mM}$ de ácido ascórbico, $2 \mathrm{mM}$ de $\beta$-mercaptoetanol e $5 \%$ de polivinilpolipirolidona (PVPP) (Itaya et al. 2002). Toda a manipulação do material durante a extração foi realizada a $5{ }^{\circ} \mathrm{C}$. O conteúdo de proteína foi determinado segundo Bradford (1976), utilizando-se albumina de soro bovino (Sigma) ( $\left.1 \mathrm{ug} \mu \mathrm{L}^{-1}\right)$ como padrão. A atividade enzimática foi determinada a partir da incubação do extrato com sacarose $0,4 \mathrm{M} \mathrm{e}$ $0,2 \mathrm{M}$ para a medida da atividade de SST e invertase, respectivamente; 1 -cestose $0,4 \mathrm{M}$ para a atividade de FFT e inulina $10 \%$ de $H$. tuberosus para a atividade de FEH, todos na proporção de 1:1 (v/v). Os ensaios foram realizados em $\mathrm{pH} 5,5$, a $30^{\circ} \mathrm{C}$, conforme Itaya et al. (2002). A análise dos produtos de incubação de SST, FFT e invertase foi feita por HPAEC/PAD em sistema de cromatografia Dionex (DX-300) utilizando-se coluna CarboPac PA-1 (4 X 250 mm). Para SST e FFT, a eluição foi realizada utilizandose o gradiente de mistura do eluente A e eluente B, descrito anteriormente para a análise dos carboidratos. Para a invertase, foi utilizado um programa isocrático de $100 \mathrm{mM}$ de hidróxido de sódio. Em ambos os casos, os potenciais aplicados ao PAD para E1 (480 $\mathrm{ms})$, E2 $(120 \mathrm{~ms})$ e E3 (60 ms) foram 0,05, 0,60 e $-0,60$, respectivamente. As atividades de SST, FFT e invertase foram calculadas com base nas áreas dos picos referentes à 1-cestose, nistose e frutose, respectivamente, utilizando-se padrões externos. A atividade de FEH foi determinada pela quantidade de frutose liberada, através da quantificação do açúcar redutor (Somogyi 1945), utilizando-se frutose (200 $\mu \mathrm{g} \mathrm{mL} \mathrm{m}^{-1}$ ) como padrão.

\section{Resultados e Discussão}

O teor de frutanos nos calos da linhagem vermelha foi de $8,1 \mathrm{mg} \mathrm{g}^{-1}$ massa fresca e nos da linhagem amarela foi de $8,8 \mathrm{mg} \mathrm{g}^{-1}$ massa fresca. Os teores desses compostos em órgãos de reserva de plantas cultivadas em campo obtidos por Fukai et al. (1997) e Itaya et al. (2002) foram de aproximadamente $85 \mathrm{mg} \mathrm{g}^{-1}$ massa fresca e $60 \mathrm{mg} \mathrm{g}^{-1}$ massa fresca, respectivamente e, portanto, muito superiores aos valores encontrados nos calos. Resultados com calos e plantas de $V$. discolor (Itaya et al. 2005) obtidas por micropropagação, e com plantas de G. macrocephala propagadas in vitro (Moreira et al. 1999) também indicaram conteúdos de frutanos inferiores aos detectados em plantas crescidas sob condições naturais. Esses resultados demonstram a preservação do metabolismo de frutanos em células menos diferenciadas e possibilitam estudos mais aprofundados visando à regulação do metabolismo desses compostos, ao aumento da produção de frutanos, bem como à obtenção de material em quantidades suficientes para estudos enzimáticos específicos.

Calos das linhagens amarela e vermelha apresentaram diferenças nas atividades das enzimas do metabolismo de frutanos, especialmente da SST e da invertase (figura 2).

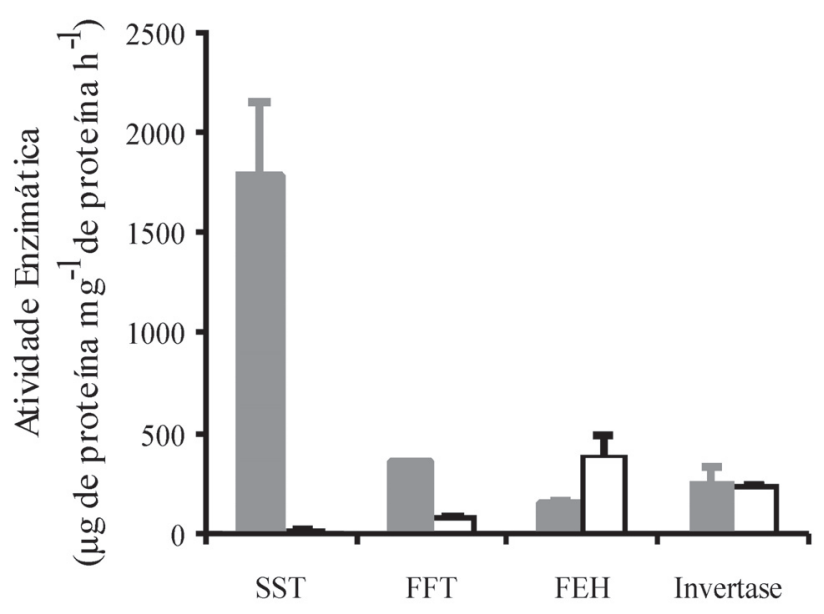

Figura 2. Atividade de sacarose: sacarose frutosiltransferase (SST) após 6 horas de incubação e de frutano: frutano frutosiltransferase de Smallanthus sonchifolius (FFT), frutano exohidrolase (FEH) e invertase após 4 horas de incubação em calos das linhagens vermelha ( $\square$ ) e amarela ( $\square)$. Barras indicam \pm erro padrão $(n=3)$.

Figure 2. Activities of sucrose:sucrose fructosyltransferase (SST) after 6 hours of incubation and of fructan:fructan fructosyltransferase (FFT), fructan exohydrolase (FEH) and invertase after 4 hours of incubation, in calli of Smallanthus sonchifolius of the red ( $\square$ ) and yellow $(\square)$ lineages. Bars indicate \pm standard error $(n=3)$. 
A figura 3 apresenta os produtos de incubação do extrato enzimático dos calos da linhagem vermelha com sacarose, para determinação das atividades de SST (figura $3 \mathrm{a}, \mathrm{b}$ ) e invertase (figura $3 \mathrm{e}, \mathrm{f}$ ), e com 1-cestose, para atividade de FFT (figura 3c, d). A atividade da SST foi detectada pela formação do trissacarídeo 1-cestose e liberação de glucose, após 6 horas de incubação. Verifica-se ainda a presença de frutose que, juntamente com parte da glucose, representam os produtos de atividade da invertase.

Diferentemente dos calos vermelhos, os calos da linhagem amarela apresentaram atividade de SST próxima de zero (figuras 2, 4a, b). Após 6 horas de incubação, a quantidade de 1-cestose formada foi muito inferior à observada nos calos vermelhos (figura 3a, b). A maior atividade de SST encontrada nos calos vermelhos (figura 2) não causou aumento no teor de frutanos nestes tecidos, uma vez que este teor foi semelhante ao encontrado nos calos amarelos. Atividade de SST elevada em plantas de S. sonchifolius (Itaya et al. 2002) e de Taraxacum officinale L. Weber ex F.H. Wigg (Van den Ende et al. 2000) cultivadas no campo foi associada a fases de crescimento e divisão celular intensos. Entretanto, como o crescimento dos calos não foi quantificado no presente estudo, não é possível correlacionar este parâmetro com a atividade diferencial da SST, de modo a confirmar esta associação em células indiferenciadas.

A atividade da FFT nos calos vermelhos foi inferior à da SST (FFT/SST <1), porém mais elevada do que a observada nos calos amarelos, que apresentaram uma razão FFT/SST >1 (figura 2). Em ambos os tipos de calos, a atividade da FFT foi detectada pelo aumento da área do pico referente à nistose, conforme ilustram as figuras $3 c, d$ e $4 c, d$, respectivamente. Semelhantemente ao observado nos calos vermelhos, Itaya et al. (2002) detectaram uma razão FFT/SST $<1$ em plantas de yacon cultivadas no campo, durante todo o ciclo de crescimento. Contudo, calos de V. discolor mantiveram a mesma razão FFT/SST $>1$, encontrada em plantas cultivadas em condições naturais (Itaya et al. 2005). Porém, a manutenção dessa característica em tecidos cultivados in vitro parece não obedecer a um padrão, visto que os calos amarelos de yacon apresentaram razão FFT/SST $>1$, diferentemente do observado em plantas ex vitro e nos calos vermelhos.

Os calos da linhagem amarela apresentaram maior atividade de FEH do que os da linhagem vermelha (figura 2). Esta atividade é consistente com a maior proporção de frutose livre, produto da FEH, e menor proporção de sacarose, inibidora desta enzima, encontrada nos calos amarelos (figura 5b). Por outro lado, a atividade mais elevada de 1-SST nos calos vermelhos é consistente com a proporção de sacarose mais elevada nesses tecidos (figura 5a). Em geral, concentrações elevadas de sacarose favorecem a síntese de frutanos (Pollock \& Cairns 1991) e inibem a FEH (Marx et al. 1997 a, b), favorecendo o controle temporal da atividade dessas enzimas que estão presentes em um mesmo compartimento celular, o vacúolo (Frehner et al. 1984).

A atividade da invertase foi maior nos calos da linhagem vermelha (figura 2), conforme demonstrado pelo aumento dos picos referentes à glucose e à frutose nas figuras $3 \mathrm{e}, \mathrm{f}$ e $4 \mathrm{e}, \mathrm{f}$. Os valores encontrados em ambos os calos, entretanto, foram superiores aos obtidos em plantas cultivadas no campo (Itaya et al. 2002), nas quais a atividade da invertase manteve-se baixa durante todo o ciclo de crescimento. Isto se deve, possivelmente, à presença de sacarose bem como de outros componentes do meio de cultura que afetaram a atividade de invertase nos calos.

Embora os calos vermelhos tenham apresentado atividade de síntese de frutanos maior que os amarelos, a análise dos carboidratos por HPAEC/PAD de ambos os calos (figura 5) revelou, além de glucose, frutose e sacarose, a presença de fruto-oligossacarídeos com grau de polimerização $(\mathrm{GP}) \leq 5$, inferior ao encontrado em raízes tuberosas de plantas sob condições naturais, que apresentam GP $\leq 15$ (Itaya et al. 2002). A linhagem vermelha apresentou maiores proporções de sacarose, 1-cestose e nistose, quando comparada à amarela, que apresentou maiores proporções de glucose e frutose. Essa diferença no perfil cromatográfico nas duas linhagens parece estar relacionada às enzimas que apresentaram maiores atividades: a de SST nos calos vermelhos, promovendo a síntese da 1-cestose com o consequiente alongamento da cadeia, e a de FEH nos calos amarelos, atuando na redução do comprimento das cadeias, conforme já sugerido por Itaya et al. (2002) para plantas de yacon crescidas no campo.

Os resultados obtidos no presente trabalho demonstram inequivocamente a presença das enzimas do metabolismo de frutanos e de frutanos com baixo GP em ambas as linhagens de calos de S. sonchifolius. Esses calos constituem um material alternativo para o estudo específico de frutosiltransferases e hidrolases visando ao conhecimento da regulação do metabolismo de frutanos, devido à atividade diferencial dessas enzimas nas linhagens vermelha e amarela e ao potencial de rápida multiplicação desse material em larga escala. 
Tempo zero
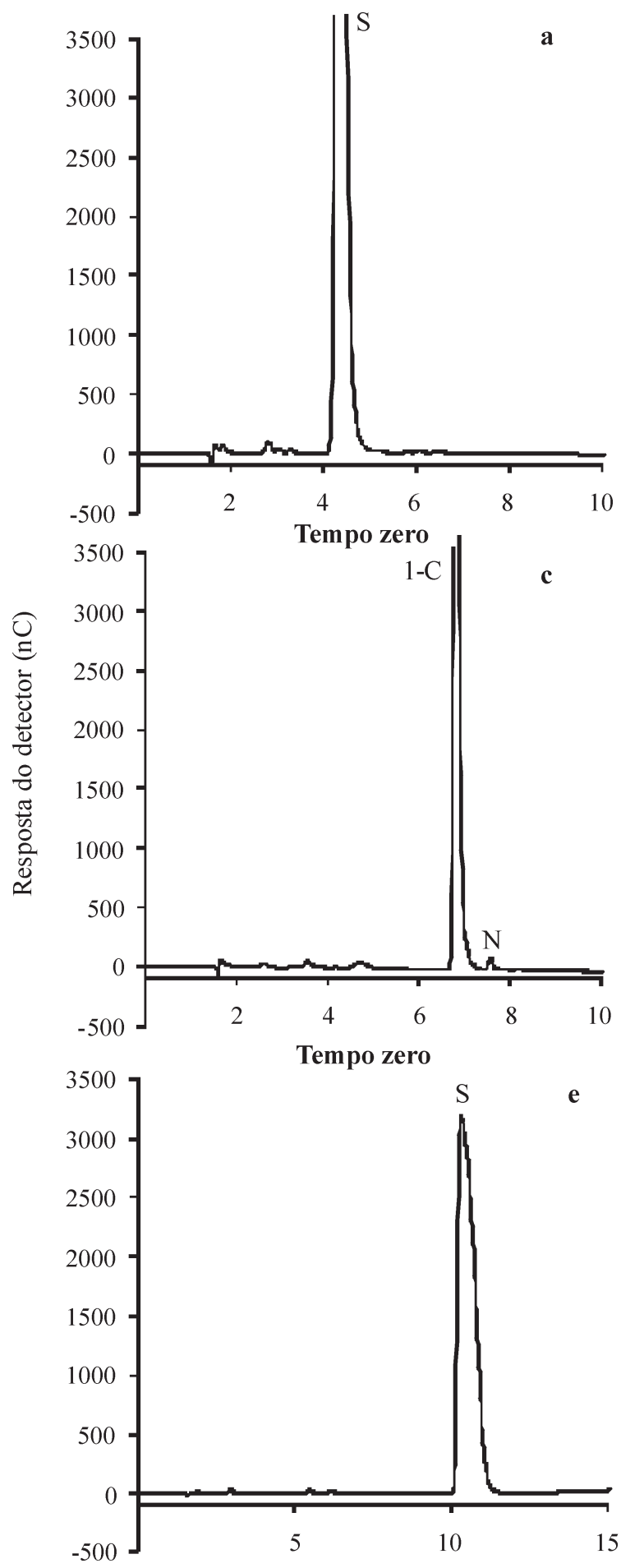

6 horas
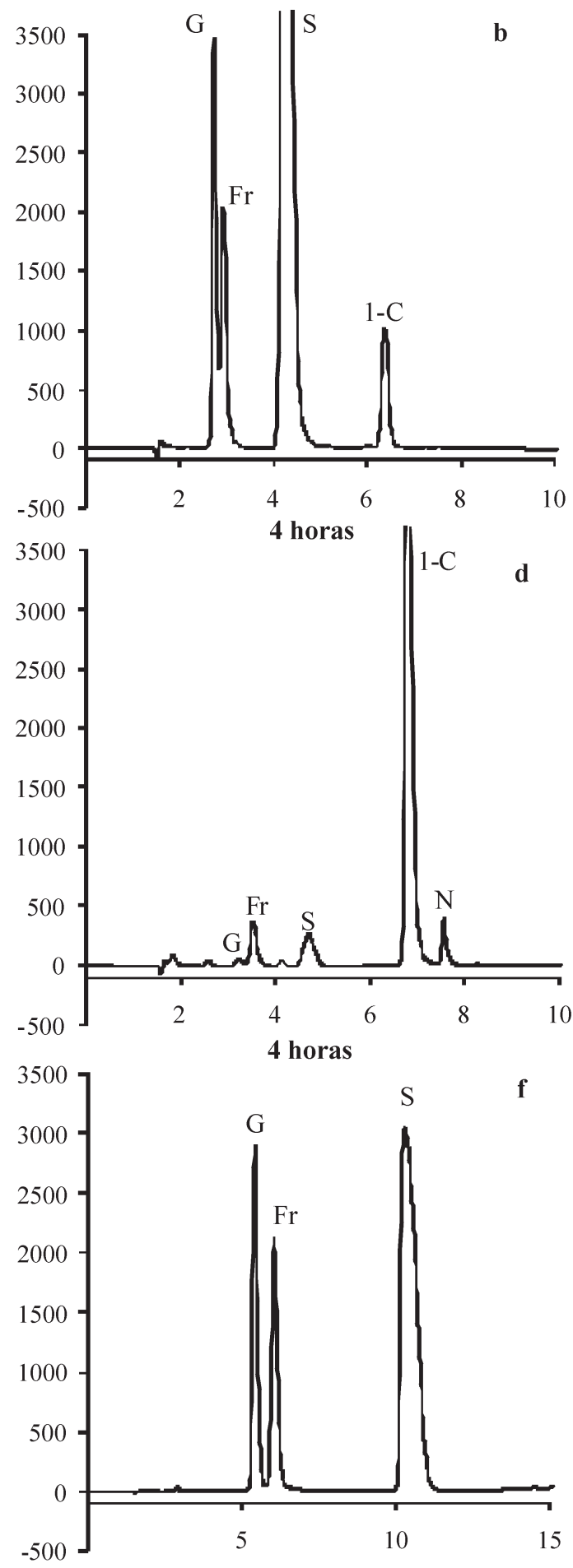

Tempo de eluição (min)

Figura 3. Análise por HPAEC/PAD dos produtos formados pela incubação de extratos enzimáticos de calos vermelhos de Smallanthus sonchifolius com sacarose 0,4 M (a-b), 0,2 M (e-f) e 1-cestose 0,4 M (c-d). G = glucose, Fr = frutose, $\mathrm{S}=$ sacarose, 1 -C = 1-cestose, $\mathrm{N}$ = nistose.

Figure 3. HPAEC/PAD analyses of incubation products of enzyme extracts of red calli of Smallanthus sonchifolius with $0.4 \mathrm{M}$ sucrose (a-b), 0.2 M sucrose (e-f) and 0.4 M 1-kestose (c-d). G = glucose, $\mathrm{Fr}=$ fructose, $\mathrm{S}=$ sucrose, 1 -C = 1-kestose, $\mathrm{N}=$ nystose. 

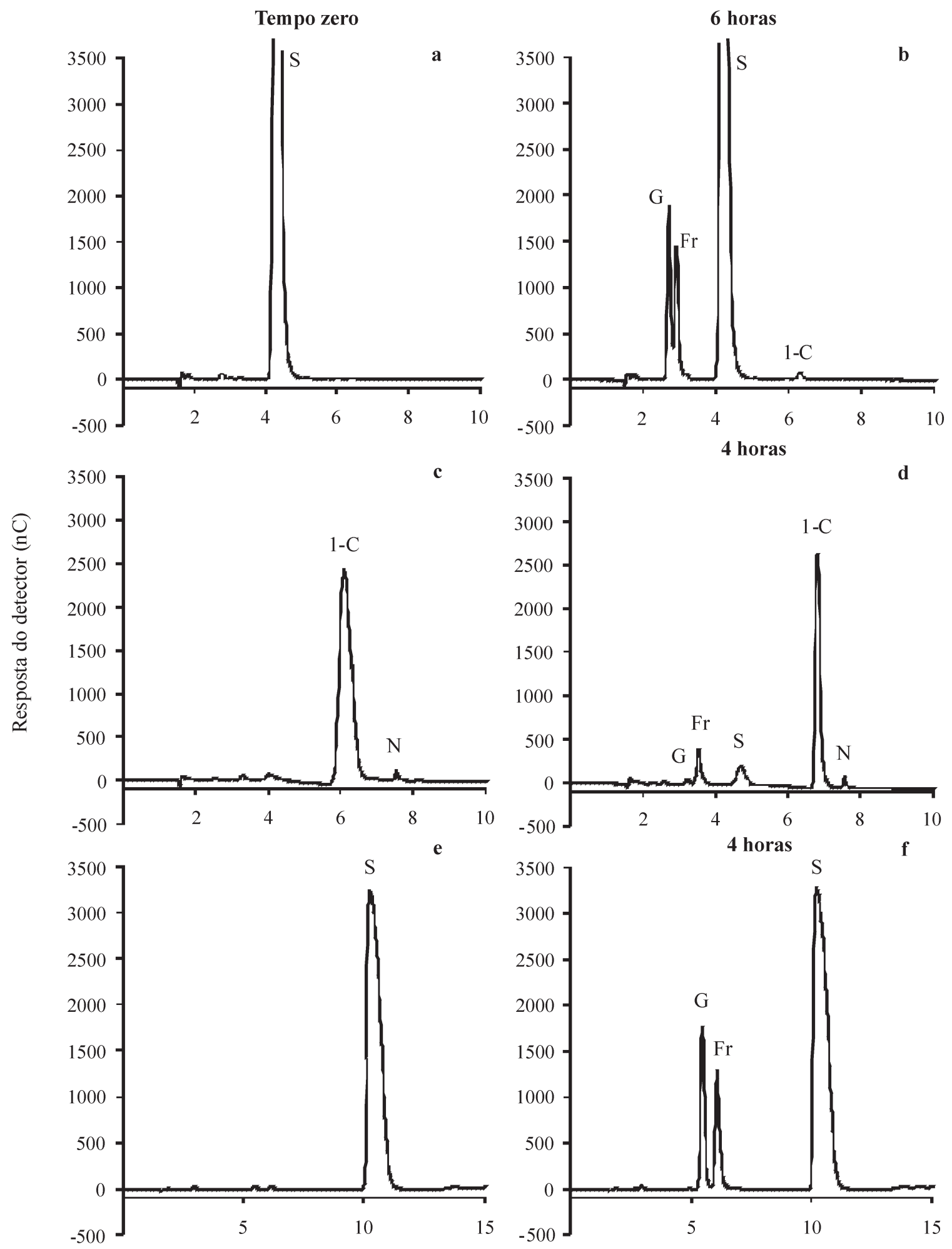

Tempo de eluição (min)

Figura 4. Análise por HPAEC/PAD dos produtos formados pela incubação de extratos enzimáticos de calos amarelos de Smallanthus sonchifolius com sacarose 0,4 M (a-b), 0,2 M (e-f) e 1-cestose 0,4 M (c-d). G = glucose, Fr $=$ frutose, $\mathrm{S}=$ sacarose, 1 - $\mathrm{C}=1$-cestose, $\mathrm{N}=$ nistose.

Figure 4. HPAEC/PAD analyses of incubation products of enzyme extracts of yellow calli of Smallanthus sonchifolius with $0.4 \mathrm{M}$ sucrose (a-b), 0.2 M sucrose (e-f) and 0.4 M 1-kestose (c-d). G = glucose, $\mathrm{Fr}=$ fructose, $\mathrm{S}=$ sucrose, 1-C = 1-kestose, $\mathrm{N}=$ nystose. 

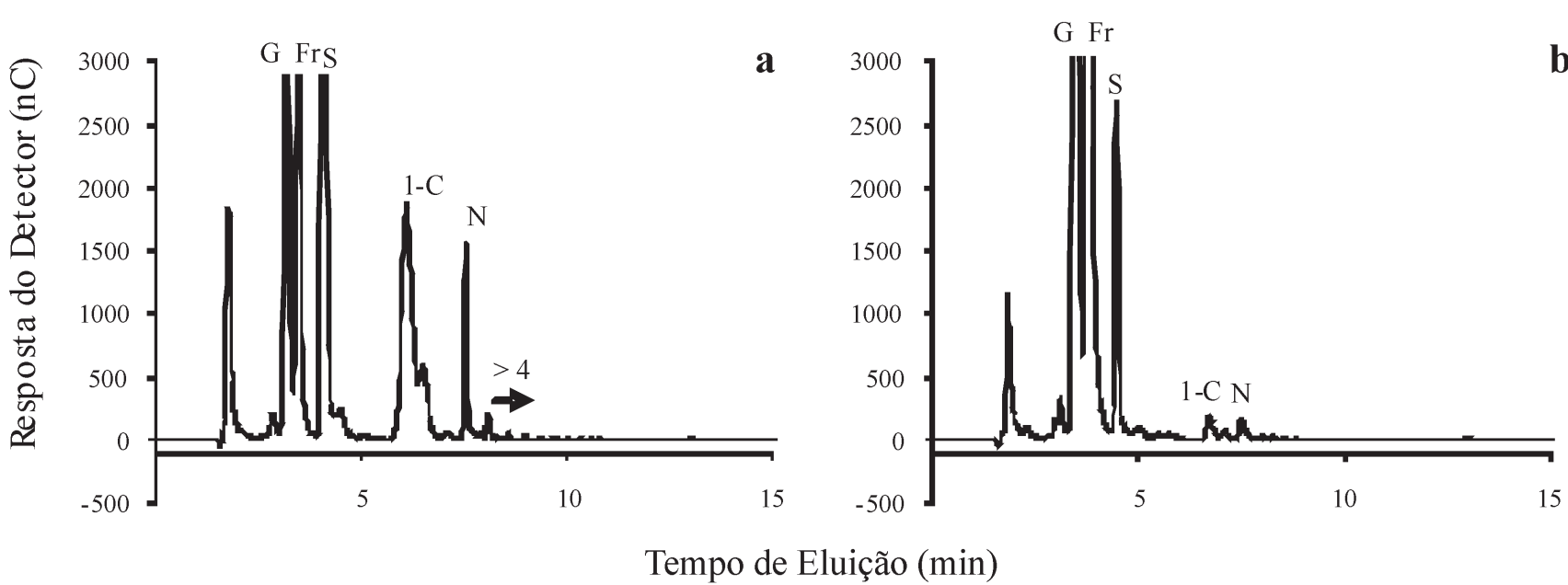

Figura 5. Análise por HPAEC/PAD dos fruto-oligossacarídeos de calos das linhagens vermelha (a) e amarela (b) de Smallanthus sonchifolius. $\mathrm{G}=$ glucose, $\mathrm{Fr}=$ frutose, $\mathrm{S}=$ sacarose, $1-\mathrm{C}=1$-cestose, $\mathrm{N}=$ nistose, $>4$ = fruto-oligossacarídeos com $\mathrm{GP}>4$.

Figure 5. HPAEC/PAD analyses of fructo-oligosaccharides from calli of Smallanthus sonchifolius of the red (a) and yellow (b) lineages. $\mathrm{G}=$ glucose, $\mathrm{Fr}=$ fructose, $\mathrm{S}=$ sucrose, $1-\mathrm{C}=1$-kestose, $\mathrm{N}=$ nystose, $>4$ = fructo-oligosaccharides with $\mathrm{DP}>4$.

\section{Agradecimentos}

À FAPESP (Proc. 98/05124-8 e Proc. 05/04139-7) e ao CNPq (Proc. 474674/04) pelo apoio financeiro. À Dra Rita de Cássia L. Figueiredo-Ribeiro pela leitura crítica do manuscrito e pelas sugestões valiosas. M.A.M.C. e V.F.O. agradecem ao CNPq pelas bolsas de Produtividade em Pesquisa e PIBIC.

\section{Literatura citada}

Abou-Mandour, A.A., Czygan, F.C., Haaß, D. \& Franz, G. 1987. Fructan synthesis in tissue culture of Symphytum officinale L.: Initiation, differentiation and metabolic activity. Planta Medica 53: 482-487.

Bradford, M.M. 1976. A rapid and sensitive method for the quantitation of microgram quantities of protein utilizing the principle of protein-dye binding. Analytical Biochemistry 72: 248-254.

Carabin, I.G.\& Flamm, W.G. 1999. Evaluation of safety of inulin and oligofructose as dietary fiber. Regulatory Toxicology and Pharmacology 30: 268-282

Carvalho, M.A.M., Pinto M.M. \& Figueiredo-Ribeiro, R.C.L. 1998. Inulin production by Vernonia herbacea as influenced by mineral fertilization and time of harvest. Revista Brasileira de Botânica 21: 281-285.

Chu, I.Y.E. \& Kurtz, S.L. 1990. Commercialization of plant micropropagation. In: P.V.Ammirato, D.A. Evans, W.R. Sharp \& Y.P.S. Bajaj (eds.). Handbook of plant cell culture. Mcgraw Hill, New York, pp. 126-164.

Edelman, J. \& Jefford, T.G. 1968. The mechanism of fructosan metabolism in higher plants as exemplified in Helianthus tuberosus. New Phytologist 67: 517-531.
Frehner, M., Keller, F. \& Wiemken, A. 1984 . Localization of fructan metabolism in the vacuoles isolated from protoplasts of Jerusalem artichoke tubers (Helianthus tuberosus L.). Journal of Plant Physiology 116: 197-208.

Fuchs,A.1993. Inulin and inulin containing crops. Elsevier, Amsterdam.

Fukai, K.,Ohno, S., Goto, K., Nanjo, F. \& Hara,Y. 1997. Seasonal fluctuations in fructans content and related activities in yacon (Polymnia sonchifolia). Soil Science and Plant Nutrition 43: 171-177.

Goto, K., Fukai, K., Hikika, J., Nanjo, F. \& Hara, Y. 1995. Isolation and structural analysis of yacon oligosaccharides. Bioscience, Biotechnology and Biochemistry 59: 2346-2347.

Grau, A. \& Rea, J. 1998. Yacon: Smallanthus sonchifolia Poep. \& Endl. In: J. Heller, M. Hermman \& J. Engles (eds.). Andean roots and tuber genetic resources. IPGRI, Rome, pp. 198-242.

Hale, A.D., Pollock, C.J. \& Dalton, S.J. 1987. Polysaccharide production in liquid cell suspension cultures of Pheum pratense L. Plant Cell Reports 6: 435-438.

Hendry, G.A.F. \& Wallace, R.K. 1993. The origin, distribuition and evolutionary significance of fructans. In: M.M. Suzuki \& N.J. Chatterton (eds). Science and tecnology of fructans. CRC Press, Boca Raton, pp. 119-139.

Hidaka, H., Eida, T., Takizawa, T. \& Tokunaga,Y. 1986. Effects of fructooligosaccharides on intestinal flora and human health. Bifidobacteria Microflora 5: 37-50.

Itaya, N.M., Carvalho, M.A.M. \& Figueiredo-Ribeiro, R.C.L. 2002. Fructosyl transferase and hydrolase 
activities in rhizophores and tuberous roots upon growth of Polymnia sonchifolia (Asteraceae). Physiologia Plantarum 116: 451-459.

Itaya, N.M., Vaz, A.P.A., Kerbauy, G.B. \& FigueiredoRibeiro, R.C.L. 2005. Produção de frutanos em calos e plântulas clonadas in vitro de Viguiera discolor Baker (Asteraceae). Acta Botanica Brasilica 19: 579-586.

Jermyn, M.A. 1956. A new method for the determination of ketohexoses in presence of aldohexoses. Nature 177: 38-39.

Kakihara, T.S., Câmara, F.L.A., Vilhena, S.M.C. \& Riera, L. 1997. Cultivo e industrialização de yacon (Polymnia sonchifolia): uma experiência brasileira. In: Congresso Latino Americano de raízes tropicais. CERAT-UNESP, São Pedro, pp. 148.

Kaur, N. \& Gupta, A.K. 2002. Applications of inulin and oligofructose in health and nutrition. Journal of Biosciences 27: 703-714.

Marx, S.P., Nösberger, J. \& Frehner, M. 1997a. Seasonal variation of fructan- $\beta$-fructosidase $(\mathrm{FEH})$ activity and characterization of a $\beta(2,1)$-linkage specific FEH from tubers of Jerusalem artichoke (Helianthus tuberosus). New Phytologist 135: 267-277.

Marx, S.P., Nösberger, J. \& Frehner, M. 1997b. Hydrolyses of fructan in grasses: a $\beta(2,6)$ linkage specific fructan- $\beta$ - fructosidase from stubble of Lolium perenne. New Phytologist 135: 279-290.

Moreira, M.F., Vieira, C.C.J. \& Zaidan, L.B.P. 1999. Efeito do fotoperíodo no crescimento e no padrão de acúmulo de frutanos em plantas aclimatizadas de Gomphrena macrocephala St.-Hil. (Amaranthaceae). Revista Brasileira de Botânica 22: 397-403.

Murashige, T. \& Skoog, F. 1962. A revised medium for rapid growth and bioassay with tabacco tissue culture. Physiologia Plantarum 15: 473-497.

Nieto, C.C. 1991. Studios agronomicos y bromatologicos em "jicama” (Polymnia sonchifolia Poep. \& Endl.). Archivos Latinoamericanos de Nutricion 41: 213-221.

Ohyama, T., Ito, O., Yasuyoshi, S., Ikarashi, T., Minamisawa, K., Kubota, M., Tsukihashi, T. \& Asami, T. 1990. Composition of storage carbohydrate in tubers of yacon (Polymnia sonchifolia). Soil Science \& Plant Nutrition 36:167-171.
Pollock, C.J. \& Cairns, A.J. 1991. Fructan metabolism in grasses and cereals. Annual Review of Plant Physiology and Plant Molecular Biology 42: 77-101.

Pollock, C.J., Cairns,A.J.,Sims, I.M. \& Housley, T.L. 1996. Fructans as reserve carbohydrates in crop plants. In: E. Zamski \& A.A.Shaffer (eds). Photoassimilate distribution in plants and crops : source - sink relationships. A.A. Marcel Dekker, New York, pp. 97-113.

Portes, M.T. \& Carvalho, M.A.M. 2006. Spatial distribution of fructans and fructan metabolizing enzymes in rhizophores of Vernonia herbacea (Vell.) Rusby (Asteraceae) in different developmental phases. Plant Science 170: 624-633.

Ritsema, T. \& Smeekens, S.C.M. 2003. Fructans: beneficial for plants and humans. Current Opinion in Plant Biology 6: 223-230.

Somogyi, M. 1945. A new reagent for the determination of sugars. Journal of Biological Chemistry 160: 61-63.

Van den Ende, W., Michiels, A., De Roover, J. \& Van Laere, A. 2002. Fructan biosynthetic and breakdown enzymes in dicots evolved from different invertases. Expression of fructan genes throughout chicory development. The Scientific World Journal 2: 1273-1287.

Van den Ende, W., Michiels, A., Van Wonterghem, D., Vergauwen, R. \& Van Laere, A. 2000. Cloning, developmental and tissue-specific expression of sucrose:sucrose 1-fructosyl transferase from Taraxacum officinale fructan localization in roots. Plant Physiology 123: 71-80.

Veramendi, J., Willmitzer, L., \& Trethewey, R.N. 1999. In vitro grown potato microtubers are a suitable system for the study of primary carbohydrate metabolism. Plant Physiology and Biochemistry 37: 693-697.

Vieira, C.C.J., Braga, M.R. \& Figueiredo-Ribeiro, R.C.L. 1995. Fructans in callus of Gomphrena macrocephala St.-Hil. Plant Cell, Tissue and Organ Culture 42: 233-238.

Vilhena,S.M.C., Câmara,F.L.A. \& Kakihara, S.T. 2000. O cultivo de yacon no Brasil. Horticultura Brasileira 18: 5-8.

Wang, X. \& Gibson, G.R. 1993. Effects of the in vitro fermentation of oligofructose and inulin by bacteria growing in the human large intestine. The Journal of Applied Bacteriology 75: 373-380. 